\title{
Peran Diplomasi Pertahanan Indonesia terhadap Pembangunan Kanal Kra untuk Menjaga Stabilitas Keamanan ASEAN
}

\author{
Rodon Pedrason \\ Direktur Jenderal Strategi Pertahanan, Kementerian Pertahanan Republik \\ Indonesia/Diplomasi Pertahanan, Universitas Pertahanan \\ Email: rodon.pedrason@idu.ac.id
}

\begin{abstract}
ABSTRAK
Penelitian ini bertujuan untuk menganalisis peran diplomasi pertahanan Indonesia terhadap pembangunan Kanal Kra yang akan dibangun oleh Thailand melalui investasi Cina sebagai upaya pembangunan jalur laut baru. Indonesia harus mempertimbangkan setiap ancaman yang datang dengan adanya pembangunan Kanal Kra tersebut. Peluang dan tantangan bagi Indonesia dengan adanya pembangunan Kanal Kra menjadi isu yang perlu untuk di luruskan agar tidak berdampak pada pertumbuhan ekonomi, politik, dan stabilitas keamanan kawasan di Asia Tenggara. Metode penelitian yang digunakan adalah desain penelitian kualitatif yang bersifat eksplanatif dengan menggunakan metode pengamatan langsung, wawancara, dan studi literatur. Adanya rute jalur laut yang baru akan menghasilkan ancaman baru diberbagai bidang, sehingga perlu bagi Indonesia untuk mempertahankan kepentingan nasional dan keamanan nasional terutama pada regional kawasan ASEAN. Untuk itu, peran diplomasi pertahanan Indonesia harus lebih intensif mengingat persoalan tersebut akan mempengaruhi stabilitas keamanan regional.
\end{abstract}

Kata Kunci: diplomasi pertahanan, Kanal Kra, stabilitas keamanan.

\section{PENDAHULUAN}

Menurut Wayne (2020) Kanal Kra merupakan bagian tersempit dari Semenanjung Malaya. Nama Kanal Kra diambil dari Isthmus Kra di Thailand yang telah lama dikenal sebagai bagian yang cocok untuk menghubungkan Laut Cina Selatan dan Samudera Hindia sebagai jalur pemotongan. Berdasarkan Rouillard dan Saito (2013) menjelaskan bahwa ide dari pembangunan Kanal Kra terjadi pada pertengahan abad ke17. Thailand pada waktu itu dikenal sebagai Kerajaan Siam ingin melakukan perubahan terhadap perdagangan. Thailand membuka negaranya bagi pedagang Eropa. Oleh sebab itu, Thailand merupakan salah satu pusat perdagangan terbesar yang ada di Asia Tenggara. Kanal Kra atau Kra Ishtmus merupakan jalur yang dibangun sebagai transportasi laut yang dilakukan melalui proses mempersingkat jalur Laut Cina Selatan menuju Samudera Hindia. Disamping itu, jalur tersebut tidak melewati Selat Malaka. Perkiraan waktu yang ditempuh menghemat 72 jam dari waktu yang selama ini melalui Selat Malaka dan berlabuh di Singapura. Disamping itu Rahman et al. (2016) menjelaskan bahwa masalah Kanal Kra merupakan gagasan yang disambut dengan baik karena menghemat biaya yang besar, tingkat keselamatan yang tinggi, dan jarak yang singkat dibandingkan menggunakan jalur Selat Malaka.

Pada tahun 2016, hampir sepertiga dari total minyak bumi global dan produk cair lainnya atau rata-rata 16 juta barel minyak per hari melewati Selat Malaka(Sa'adah, Fauzi, \& Juanda, 2017). Sebagai rute alternatif ke Selat Malaka, Kanal Kra cenderung memberikan dampak bagi kapal-kapal yang melintas. Pusat pelayaran internasional dan penerima manfaat jangka panjang utama dari Selat Alacca adalah Singapura, yaitu berupa dampak negatif secara ekonomi dan politik setelah Kanal Kra dibangun(Heng \& Yip, 2017). Jalur maritim di Selat Malaka merupakan jalur laut yang digunakan saat ini sebagai poros perdagangan di Asia Tenggara dengan pelabuhan kapal-kapal besar yang menjadikan pelabuhan Singapura sebagai 
rest area(Ho, 2009). Pondasi dan reputasi yang telah dibagun oleh Singapura merupakan sesuatu yang baik selama ini, pertimbangan untuk layanan dan fasilitas menjadikan optimistis tersendiri bagi Singapura bahwa pelabuhannya tidak akan mati tergerus oleh adanya pembangunan Kanal Kra(Peng Er, 2018). Akan tetapi, kegiatan bisnis maritim di Selat Malaka dapat terpengaruh dengan adanya jalur baru tersebut. Pembentukan jalur laut baru yang dapat diakses kan berpengaruh terhadap perekonomian pada regional ASEAN.

Kartini (2016) mengatakan bahwa kebijakan Kanal Kra merupakan Jalur Sutra Baru Cina yang diprediksi akan mendominasi perekonomian di Asia. Hal ini dikarenakan dengan adanya jalur baru tersebut akan menguntungkan Tiongkok karena biaya untuk ekspor serta impor dari negaranya menjadi lebih rendah. Disisi lain, Jalur Sutra Baru Cina yang mencakup menjadi sebuah perpaduan dari kekuatan geopolitik dan geoekonomi. Perpaduan tersebut dilakukan untuk menghubungkan wilayah Eurasia dan Cina sebagai pusatnya. Pengembangan kerangka transit Kanal Kra, pertama-tama diperlukan untuk mengidentifikasi transit tanker saat ini. Ini dicapai dari dua sumber utama dengan masing-masing tipe data yang berkontribusi pada identifikasi rute dan jenis kapal dari transit tanker. Kanal Kra yang diusulkan dan dampaknya pada pasar tanker dari perspektif ekonomi, stabilitas keamanan, politik, dan pembangunan regional ASEAN akan memberikan banyak keuntungan bagi kapal-kapal ketika tarif timecharter rendah dan harga bahan bakar tinggi. dampak dari pembangunan Kanal Kra terhadap politik ekonomi, sosial, teknologi, dan lingkungan yang berhubungan dengan keamanan bagi wilayah sekitarnya(Hamzah, Forbes, Jalil, \& Basiron, 2014). Ada beberapa masalah yang dihadapi dengan adanya pembangunan Kanal Kra ini di wilayah ASEAN. Oleh sebab itu, Indonesia menjadi satu negara yang berdekatan dengan lintas Kanal Kra di selatan Thailand tersebut. Pembangunan Kanal Kra memberikan dampak ekonomi dan politik global. Sulong (2012) mengatakan efek ekonomi dari interdependensi telah dieksplorasi secara ekstensif dalam literatur, dan telah ditunjukkan bahwa perubahan dalam satu pasar mempengaruhi pasar lain, terutama dalam konteks Asia Tenggara. Meningkatnya interdependensi pasar yang terintegrasi secara regional juga memaparkan negara untuk efek perubahan sosial dan politik. Bahkan jika negara tidak memiliki ikatan ekonomi "formal" dengan lembaga supranasional. Oleh karena itu, secara tiba-tiba perubahan dan gangguan ke pasar negara dapat menyebabkan ketidakpastian dan meningkatkan risiko melakukan bisnis di negara tertentu(Radityo, Rara, Amelia, \& Efraim, 2019).

ASEAN sebagai asosiasi regional di Asia Tenggara telah memberikan banyak manfaat ekonomi dan politik bagi masing-masing negara anggotanya, banyak yang berpendapat bahwa sistem perbedaan pasar ditambah sengketa sejarah laten antara anggota memiliki potensi menyebabkan ketegangan dan konflik, yang dapat memiliki implikasi negatif untuk kerjasama regional(Rahawarin, Ahmad, \& Octavian, 2019). Karena sejarah dan kondisi politik saat ini di wilayah ASEAN, perkembangan Kanal Kra dapat menciptakan risiko sosio-politik di wilayah Asia Tenggara secara keseluruhan, termasuk Indonesia sebagai salah satu negara di kawasan tersebut(Gita, Persada, \& Setyawanta, 2021). Pembangunan Kanal Kra menjadi diskusi panjang di tanah air. Peluang dan tantangan bagi Indonesia dengan adanya pembangunan Kanal Kra menjadi isu yang perlu untuk di luruskan agar tidak berdampak pada pertumbuhan ekonomi, politik, dan stabilitas keamanan kawasan di Asia Tenggara. Strategi Indonesia diharapkan mampu bersaing dengan negara-negara yang terkena imbas dari pembangunan ini melalui diplomasi pertahanan(Ridwan \& Yulianto, 2010). Adanya rute jalur laut yang baru akan menghasilkan ancaman baru terutama di bagian maritim, sehingga perlu bagi Indonesia untuk mempertahankan kepentingan nasional dan keamanan nasional.

Berdasarkan kajian yang telah dibahas menunjukkan bahwa Indonesia harus mempertimbangkan setiap ancaman yang datang karena pembangunan Kanal Kra tersebut. Keterlibatan Indonesia pada pembangunan ini bisa menjadi peluang dan tantangan yang perlu 
dihadapi terutama di bidang ekonomi, politik, dan keamanan. Oleh karena itu tujuan adanya penelitian ini untuk mengetahui stabilitas keamanan negara-negara ASEAN dengan adanya pembangunan Kanal Kra yang dibangun oleh pemerintahan Thailand di Semenanjung Malaya. Dan juga untuk mengetahui diplomasi pertahanan Indonesia terhadap pembangunan Kanal Kra yang dibangun oleh Thailand sebagai rute laut baru bagi kapal-kapal besar dan pengaruhnya terhadap ekonomi, politik, dan stabilitas keamanan kawasan ASEAN

\section{METODOLOGI PENELITIAN}

Metode penelitian ini dilakukan melalui desain penelitian kualitatif yang bersifat eksplanatif. Sehingga, studi ini memiliki menganalisis peran diplomasi pertahanan Indonesia terhadap pembangunan Kanal Kra guna mengedepankan kepentingan Indonesia di Kawasan Asia Tenggara. Untuk melakukan analisis terkait peran diplomasi, studi ini menggunakan teknik pengumpulan data pengamatan langsung, wawancara, dan studi literatur (Moleong, 2017). Pada proses pengamatan langsung dilakukan dengan mengamati beragam data yang diperoleh dari permasalahan yang muncul berupa isu-isu yang berkembang karena adanya pembangunan Kanal Kra menghasilkan berbagai permasalahan yang dihadapi dan ancaman yang muncul akibat pembangunan tersebut.

Pada proses wawancara, peneliti melakukan kegiatan tatap muka secara langsung. Disamping itu, karena pandemi Covid-19 pengumpulan data juga dilakukan menggunakan alat komunikasi lainnya seperti Zoom dan Google Meet dengan tujuan mendapatkan informasi agar dapat memahami lebih lanjut mengenai fenomena yang terjadi. Fenomena yang dikumpulkan berhubungan dengan pembangunan Kanal Kra terhadap stabilitas keamanan ASEAN. Proses pemilihan partisipan dilakukan dengan purposive sampling yaitu mengidentifikasi sepuluh informan dengan latar belakang kompetensi di bidang keamanan dan pembangunan Kanal Kra (Sujarweni, 2014). Untuk menjaga etika penelitian, nama yang dicantumkan adalah nama samaran. Berikut ini daftar informan dalam penelitian:

Table 1. Daftar Informan

\begin{tabular}{|c|c|c|c|}
\hline No & Nama & Jenis Kelamin & Bidang \\
\hline 1 & Informan 1 & Laki-Laki & Kementerian Luar Negeri \\
\hline 2 & Informan 2 & Laki-Laki & Kementerian Luar Negeri \\
\hline 3 & Informan 3 & Laki-Laki & Kementerian Pertahanan \\
\hline 4 & Informan 4 & Laki-Laki & Kementerian Pertahanan \\
\hline 5 & Informan 5 & Laki-Laki & $\begin{array}{l}\text { Kementerian Koordinator Bidang } \\
\text { Kemaritiman }\end{array}$ \\
\hline 6 & Informan 6 & Laki-Laki & $\begin{array}{l}\text { Kementerian Koordinator Bidang } \\
\text { Kemaritiman }\end{array}$ \\
\hline 7 & Informan 7 & Laki-Laki & $\begin{array}{l}\text { Kementerian Koordinator Bidang Politik, } \\
\text { Hukum, dan Keamanan }\end{array}$ \\
\hline 8 & Informan 8 & Laki-Laki & $\begin{array}{l}\text { Kementerian Koordinator Bidang Politik, } \\
\text { Hukum, dan Keamanan }\end{array}$ \\
\hline 9 & Informan 9 & Laki-Laki & $\begin{array}{l}\text { Kementerian Koordinator Bidang } \\
\text { Kemaritiman }\end{array}$ \\
\hline 10 & Informan 10 & Laki-Laki & $\begin{array}{l}\text { Kementerian Koordinator Bidang Politik, } \\
\text { Hukum, dan Keamanan }\end{array}$ \\
\hline
\end{tabular}


Pengumpulan data juga dilakukan dengan studi literatur yaitu mencari referensi. Disisi lain, untuk memperkuat permasalahan dengan teori dan dokumen yang digunakan dalam melakukan penelitian. Verifikasi dilakukan dengan triangulasi. Triangulasi didefinisikan sebagai teknik pengumpulan data dengan menggabungkan beberapa sumber data yang berbeda (Mukhtar, 2013). Peneliti menggunakan beberapa teknik yang berbeda dalam memverifikasi data untuk mendapatkan data dari satu subjek atau sumber yang sama. Dalam penelitian ini, peneliti mewawancarai informan tentang Kanal Kra dan Asia Tenggara. Kemudian menganalisis isu Kanal Kra. Sehingga peneliti mendapatkan informasi dari berbagai cara yaitu wawancara, dan dokumentasi(Moleong, 2017).

Analisis data dalam penelitian ini dilakukan dengan proses di mana peneliti secara sistematis mencari dan mengatur data. Analisis data dalam penelitian ini menggunakan analisis data kualitatif yang melibatkan pengkodean. Pengkodean ini disesuaikan dengan kebutuhan penelitian. Selain itu, analisis data juga dilakukan dengan tahap reduksi data. Pada proses reduksi data peneliti merangkum, memilih hal yang pokok, dan menemukan topik terkait Kanal Kra. Setelah reduksi data langkah selanjutnya dalam menganalisis data adalah penyajian data. Proses ini dilakukan dalam bentuk deskriptif. Pada tahap terakhir ini analisis data yaitu penarikan kesimpulan. Disini peneliti mulai melihat apa itu data. Peneliti memeriksa semua entri dengan kode yang sama dan kemudian menggabungkan kategori-kategori ini dan menemukan hubungan di antara kategori-kategori tersebut(Miles, Huberman, \& Saldana, 2014).

\section{HASIL PENELITIAN}

\section{Kanal Kra dan Asia Tenggara}

Perekonomian Thailand sangat tergantung pada perdagangan internasional, sistem transportasi yang dikembangkan sepenuhnya diperlukan. Hampir semua Thailand memiliki fasilitas pelabuhan, bandara, jalan, dan kereta api yang dikembangkan dengan baik untuk memenuhi kebutuhannya. Karena sebagian besar ekspor Thailand adalah komoditas pertanian yang besar dan berbiaya rendah, lebih dari 90 persen ekspor Thailand diangkut lewat laut. Hanya produkproduk industrial yang lebih ringan dan barang-barang yang mudah rusak seperti buah-buahan, bunga-bungaan dan bahan makanan, di mana Thailand mengekspor dalam jumlah yang cukup besar, berpergian melalui udara ke tujuan pasar Thailand(Hambalie, 2020). Kondisi ini menjelaskan pentingnya jalur atau akses laut bagi negara tersebut untuk meningkatkan perekonomian sekaligus menjadi negara transit bagi negara-negara lain yang menggunakan jalur laut sebagai sarana transportasi dalam perputaran transportasi pasar.

Pembangunan proyek Kanal Kra akan menjadi pukulan bagi sisa-sisa kerajaan maritim Inggris, dimana Singapura dan Selat Malaka tetap merupakan pos terdepan. Menurut Stetnstein dalam (Monika, Baiquni, \& Hadi, 2020) Kanal Kra akan secara signifikan mempersingkat rute perdagangan ini(Rouillard \& Saito, 2013). Hal ini akan menjadi tantangan tersendiri bagi Singapura untuk tetap mengandalkan pelabuhan internasional sebagai wilayah transit kapalkapal dunia yang melintasi Selat Malaka. Di sisi lain, selain Thailand yang mendapatkan keuntungan signifikan. Myanmar dan Vietnam juga akan mendapat manfaat langsung dari proyek-proyek pembangunan yang terkait dengan Kanal Kra. Kota-kota pesisir di Myanmar dan Thailand saat ini menawarkan saluran air strategis ke Selat Malaka dengan penciptaan Kanal Kra. Hal ini akan menjadi dua kali lipat pentingnya. Misalnya, pada Mei 2008, Thailand dan Myanmar menandatangani Memorandum of Understanding (MoU) untuk meneruskan proyek membangun pelabuhan laut dalam di Dawei, yang juga dikenal sebagai Pelabuhan Dawei. Penciptaan Kanal Kra akan mendukung pengembangan pelabuhan laut dalam yang 
terkait dengan kawasan industri di Dawei, yang sebelumnya disebut Tavoy, di Myanmar Selatan.

Pengembangan Kanal Kra juga akan menguntungkan Laos. Oleh sebab itu, sebuah negara seperti Laos sangat bergantung pada kondisi perdagangan untuk mempertahankan pertumbuhan ekonominya. Sehingga hal itu bergantung pada negara tetangga seperti Thailand untuk mengirim ekspor ke luar kawasan. Setiap bentuk pembangunan infrastruktur Pengembangan Kanal Kra juga akan menguntungkan Laos. Sebuah negara kunci-daratan, Laos sangat bergantung pada perdagangan untuk mempertahankan pertumbuhan ekonominya(Rahmadani, Kusmanto, \& Warjio, 2019). Hal tersebut bergantung pada negara tetangganya, terutama Thailand, untuk mengirim ekspornya ke luar kawasan. Oleh karena itu, setiap bentuk pembangunan infrastruktur yang akan meningkatkan aktivitas perdagangan di Thailand pada akhirnya akan menguntungkan perekonomian Laos juga. Namun persoalan ini tidak mudah untuk dibahas, mengingat keberadaan Singapura yang menderita kerugian, serta negaranegara lain yang justru tidak mengalami dampak signifikan terhadap ada atau tidaknya pembangunan Kanal Kra. Hal tersebut akan mempengaruhi kepentingan nasional hampir seluruh negara, terutama Singapura. Negara tersebut akan mengalami kerugian yang sangat besar jika pembangunan Kanal Kra terealisasi sesuai keinginan pemerintahan Thailand. Kondisi tersebut akan sangat membuat Singapura berada pada situasi sulit pada persoalan ekonominya, mengingat selama ini negara tersebut bergantung pada peran pelabuhan internasionalnya yang selama ini sebagai kekuatan ekonomi Singapura. Pembangunan Kanal Kra ini juga memberikan beragam ruang pilihan dari akses laut untuk mempermuah aktifitas ekonomi. Meskipun pembangunan yang dilakukan memberikan keuntungan secara ekonomi tetapi juga terdapat kekhawatiran. Salah satunya adalah kesulitan dalam konstruksi masalah politik. Hasil penelitian Heng dan Yip (2017) menunjukkan bahwa sepertiga warga Thailand melakukan penentangan Kanal Kra karena takut akan lingkungan politik yang tidak stabil. Menariknya, Kanal Kra menarik banyak transit. Hal ini berhubungan dengan Singapura dimana pusat pelayaranan Internasional dan penerima manfaat jangka panjang utama dari transit Selat Malaka, dapat terkena dampak negatif secara ekonomi dan politik.

"Menurut saya, berkaitan dengan Selat Malaka, banyak keunggulan kompetitif yang sesuai dengan peran khususnya. Sedangkan bagi Cina, Selat Malaka memiliki masalah yang pelik. Salah satu masalah yang terjadi adalah peningkatan serangan perompak. Disamping itu juga terjadi peredaran ilegal dan persoalan maritim yang belum terselesaikan. Selain itu, Selat Malaka juga adalah salah satu peisisir laut tersibuk. Dimana laut tersebut menuju Malaysia, Indonesia dan Singapura." (Informan 2, 2021).

"Menurut saya, Cina bukan hanya berupaya untuk menjaga jalur laut namun negara tersebut juga memajukan transportasi darat. Dengan kata lain negara tersebut berusaha menemukan jalan lain untuk mencapai akses ke Teluk Bengal dan Lautan Hindia. Hal itu dilakukan dengan melakukan pemotongan jalur Malaka" (Informan 4, 2021).

Hasil wawancara tersebut menunjukkan bahwa Cina selalu melakukan upaya untuk meningkatkan pencarian jalur yang baru. Perkembangan Kanal Kra di wilayah yang penuh konflik ini menimbulkan kekhawatiran bahwa hal tersebut akan mengintensifkan kekerasan separatis di provinsi provinsi selatan Thailand, yang pada akhirnya akan mengganggu perdagangan dan menghambat kegiatan investasi asing di daerah tersebut. Kejadian-kejadian ini juga merusak hubungan diplomatik Thailand dengan negara-negara sekitar, seperti Malaysia, yang secara terbuka menentang tindakan keras pemerintah Thailand. Oleh sebab itu, hubungan antara Malaysia dan Thailand memburuk. 
Keprihatinan besar lainnya tentang proyek Kanal Kra adalah masalah keamanan nasional. Para penentang percaya bahwa saluran itu mungkin mengancam kepentingan dari negara tetangga Thailand. Oleh karena itu, Thailand harus menghadapi intervensi dari negaranegara tersebut ketika proyek selesai. Pengaruh luar ini akan mengancam keamanan Thailand. Dengan adanya pro-kontra terkait pembangunan Kanal Kra, maka dipastikan stabilitas politik dan keamanan tidak hanya menyangkut posisi Singapura dan Malaysia yang menentang pembangunan tersebut, namun juga berujung pada persoalan isu-isu ancaman non tradisional yang meliputi aktor-aktor non negara, seperti kelompok-kelompok bajak laut serta kesiapan sosial masyarakat yang terkena dampak dari pembangunan Kanal Kra. Disamping itu, persoalan stabilitas politik dan keamanan akan menjadi tantangan terbesar yang dihadapi negara-negara ASEAN ketika pergeseran geopolitik dari Selat Malak menuju Kanal Kra.

\section{ASEAN dalam Isu Kanal Kra}

Pengembangan Kanal Kra dapat dilihat sebagai proyek yang diperlukan yang dapat menyelamatkan kawasan dari resesi ekonomi karena dapat membawa investasi yang sangat dibutuhkan untuk ekonomi Thailand yang akan menghasilkan peningkatan kegiatan ekonomi bagi negara dan ASEAN secara keseluruhan. Tetapi di sisi lain, jika Thailand melakukan proyek mega mahal ini, itu akan menciptakan sejumlah besar utang. Karena perkiraan biaya pembangunan kanal, Thailand telah mendekati berbagai investor potensial untuk mendanai proyek tersebut. Saat ini, Cina adalah pendukung utama mega-proyek. Minat dan keinginan Cina untuk berinvestasi dalam pengembangan Kanal Kra dan implikasi yang mungkin bagi wilayah keterlibatan China menjadi sumber kekhawatiran bagi banyak negara di kawasan ini. Oleh sebab itu, bila Kanal Kra berhasil dibangun maka akan berfungsi sebagai rute perdagangan yang signifikan. Hal ini tidak hanya untuk China, tetapi juga untuk negara-negara seperti Jepang, Korea Selatan dan India. Disisi lain, karena kanal berada di wilayah Thailand, kebijakan luar negeri dari negara-negara yang berencana untuk mengakses kanal ikut berubah dan dapat menggeser keseimbangan kekuatan di dalam ASEAN. Kekuatan tersebut terutama dalam hal perdagangan dan kekuatan ekonomi. Kanal Kra pasti akan mengubah lalu lintas perjalanan jauh dari Selat Malaka sehingga menghilangkan sumber pertumbuhan ekonomi utama Malaysia dan Singapura.

Disamping itu, lalu lintas dan perdagangan yang dihasilkan oleh Selat Malaka telah memainkan peran utama dalam pertumbuhan ekonomi baik Malaysia dan Singapura. Tidak mengherankan bila lebih dari 80 persen perdagangan Malaysia melewati Selat memanfaatkan pelabuhan-pelabuhan utama seperti Port Klang dan Pelabuhan Tanjung Pelepas. Tidak dapat dibayangkan Kanal Kra mungkin dibangun lebih cepat dari yang diantisipasi(Heng \& Yip, 2017). Jika ini terjadi, Kanal Kra dapat menjadi pengubah permainan navigasi, perdagangan, dan geopolitik di Asia Timur. Hasil analisis penelitian ini menunjukkan bahwa faktor risiko politik terorisme dan penyebaran kekerasan separatis juga memiliki kemampuan untuk berubah menjadi masalah regional yang dapat membahayakan keamanan serta stabilitas semua negara di kawasan ini.

Seperti yang diketahui bahwa negara-negara Asia Tenggara terdiri dari masyarakat dengan berbagai perbedaan etnis, agama, budaya, ekonomi, dan ideologi politik. Oleh karena itu wilayah ini telah diketahui menderita berbagai konflik internal dan antar negara selama bertahun-tahun. Dengan keragaman sosial dan konflik yang jelas di kawasan ini, masingmasing negara dan wilayah secara keseluruhan diketahui memiliki tingkat risiko politik yang tinggi bahkan pada hari sebelumnya. Misalnya, Indonesia, Thailand, dan Filipina merupakan salah satu negara yang telah mencatat fluktuasi serta peningkatan peringkat risiko sepanjang tahun 2000-an, menunjukkan lingkungan risiko politik yang tinggi. Meskipun negara-negara Asia Tenggara diintegrasikan melalui ASEAN, tindakan mereka tidak diatur oleh undangundang formal tetapi lebih didasarkan pada semangat kerjasama sukarela dan penghormatan 
terhadap prinsip kedaulatan. Oleh karena itu, hubungan antara anggota ASEAN bergantung pada rasa kepercayaan dan keyakinan dalam tujuan bersama. Namun demikian, hubungan bisa tegang ketika konflik kepentingan terjadi, terutama mengenai masalah-masalah historis yang belum terselesaikan yang sebagian besar terkait dengan perbedaan etnis dan agama atau masalah-masalah teritorial. Kehadiran berbagai kelompok agama dan divisi etnis di antara masyarakat anggota ASEAN menetapkan panggung untuk lingkungan berisiko tinggi di wilayah tersebut.

"Berdasarkan hasil pengamatan yang dilakukan, pada kondisi ini peran ASEAN sangat lemah, terutama ketika dihadapkan pada kepentingan nasional masing-masing negara sekaligus campur tangan negara besar di luar kawasan. Sehingga, ketidakpastian stabilitas hubungan intra-ASEAN tertentu dapat dianggap sebagai risiko, terutama bagi mereka yang bergantung pada stabilitas kebijakan yang berbasis ASEAN." (Informan $1,2021)$

Hasil wawancara yang dilakukan kepada Informan 1 menunjukkan bahwa kerja sama ASEAN dipersulit oleh sifat institusinya yang tidak mengikat serta oleh wilayah geografisnya yang tersebar. Oleh karena itu, meskipun hubungan infrastruktur yang efisien melalui transportasi dan telekomunikasi sangat penting untuk membantu mendorong solidaritas ASEAN yang lebih besar, mereka juga dapat membagi maritim dan daratan Asia Tenggara, yang semakin memperlebar kesenjangan sosialekonomi.

\section{PEMBAHASAN}

Disisi lain, Kanal Kra juga secara geografis akan membagi daratan Asia Tenggara dari maritim Asia Tenggara. Hal ini juga dapat digunakan untuk mempengaruhi permainan kekuasaan antara negara-negara besar seperti Amerika Serikat, India, dan Cina. Hasil analisis ini menunjukkan bahwa keberadaan Amerika Serikat, India, dan Cina yang akan saling berkompetisi akan membuka ruang permusuhan serta friksi konflik yang dapat mendorong negara-negara di Asia Tenggara terbagi ke dalam beberapa blok. Sehingga, dampaknya akan berujung pada keberpihakan atau memilih beraliansi dan beroposisi. Menurut Trommer (2014) hubungan bilateral merupakan bagian penting dari pembangunan regional Asia Tenggara. Oleh karena itu, ASEAN tidak memiliki kekuatan kelembagaan dari organisasi seperti Uni Eropa. Dengan demikian, hubungan Cina saat ini dengan negara-negara seperti Thailand, Myanmar, dan Vietnam akan menguat jika Kanal Kra dibangun. Kondisi tersebut dapat merusak pengaruh ASEAN pada masa depan Asia Tenggara sebagai kawasan terpadu. Minat daerah bisa sangat mungkin bersaing dengan kepentingan nasional individu anggota yang memiliki hubungan bilateral ekonomi dan politik yang kuat dengan Cina. Selain itu, tidak hanya memicu konflik antara negara-negara anggota ASEAN sendiri, namun juga akan mempertanyakan kredibilitas ASEAN dan kepercayaan internasional terhadap peran ASEAN di regional.

Indonesia merupakan negara yang rentan terhadap perkembangan geopolitik. Hal ini terjadi dikarenakan adanya posisi geostrategis. Munculnya Cina dan strategi rebalancing Amerika Serikat sudah menjadi sebuah tema dominan di wilayah Asia Timur(Biasane, Fauzi, Monintja, \& Soedharma, 2011). Terlepas dari volume perdagangan bilateral yang signifikan, pihak pemerintah Indonesia tetap dalam kondisi sadar terkait dampak potensial dari meningkatnya persaingan Tiongkok dengan Amerika Serikat terhadap keamanan regional. Sengketa yang terus berlangsung di Laut Cina Selatan juga menjadi hambatan utama bagi perdamaian dan stabilitas di dalam Asosiasi Negara-negara Asia Tenggara (ASEAN). Didorong oleh perubahan dalam doktrin militer, kecurigaan regional yang bertahan lama, dan sisi pasokan perdagangan senjata global yang terus meningkat, Indonesia semakin khawatir tentang laju cepat modernisasi militer regional. Oleh sebab itu untuk memetakan situasi terkait 
Kanal Kra harus menjadi prioritas bagi Indonesia untuk menghindari friksi politik yang berpotensi berkembang. Karena itu pemahaman situasi terhadap perkembangan isu tersebut menjadi modal penting bagi Indonesia seperti Terdapat motivasi ekonomi yang besar oleh Thailand. Disisi lain, arah diplomasi pertahanan Indonesia, jika Kanal Kra berhasil dibangun, sebaiknya tetap mengedepankan berbagai celah kerjasama, seperti patroli militer, kerjasama industri pertahanan dalam alutsista kekuatan laut, serta mendorong berbagai kesepakatan geopolitik ke level regional untuk secara bersama merumuskan kebijakan counter-terrorism and piracy(Sartono, Prakoso, \& Suseto, 2019). Sebaliknya, jika pembangunan Kanal Kra masih belum menemui titik temu atau masih berada pada situasi yang tidak pasti, maka diplomasi pertahanan Indonesia sebaiknya Tetap mengedepankan implementasi kebijakan diplomasi pertahanan yang telah berjalan, seperti patroli militer bersama negara-negara ASEAN di Selat Malaka, terutama bersama Singapura dan Malaysia.

\section{KESIMPULAN}

Kanal Kra akan menjadi mega proyek, sebuah lorong yang akan menghubungkan Laut Cina Selatan dan Samudera Hindia. Meskipun Kanal Kra yang diusulkan diproyeksikan untuk memberikan banyak manfaat ekonomi dan perdagangan ke Thailand, dan ke wilayah secara keseluruhan, langkah-langkah menuju pengembangannya belum diambil. Stabilitas keamanan menjadi perdebatan dengan adanya pembangunan kanal Kra tersebut, terutama hubungan antar negara di kawasan ASEAN. Indonesia sebagai salah satu negara di kawasan ASEAN perlu untuk mengkaji pembangunan kanal Kra tersebut demi kepentingan nasionalnya dalam rangka menjaga stabilitas keamanan melalui diplomasi pertahanan. Arah diplomasi pertahanan Indonesia terhadap pembangunan Kanal Kra mengedepankan pada posisi netral atau hegding untuk menghindari arus konflik antara Amerika Serikat dan Cina. Dengan begitu, kebijakan Indonesia dianggap tidak berseberangan dengan kedua negara besar tersebut. Diplomasi pertahanan Indonesia perlu membangun hubungan yang lebih intensif dengan Thailand mengingat peran kekuatan laut Thailand dalam menjaga keamanan Kanal Kra sesuai dengan langkah pemerintah Indonesia saat ini, yaitu Poros Maritim Dunia. Untuk itu, berbagai celah kerjasama, seperti patroli militer, kerjasama industri pertahanan dalam alutsista kekuatan laut, serta mendorong berbagai kesepakatan geopolitik ke level regional untuk secara bersama merumuskan kebijakan counter-terrorism and piracy. Selain itu, pembangunan Kanal Kra yang akan menyisakan berbagai persoalan ancaman non tradisional, memerlukan campur tangan Indonesia dalam pembangunan kerjasama bilateral dengan Thailand atau mendorong persoalan tersebut ke ASEAN. Untuk itu, peran diplomasi pertahanan Indonesia harus lebih intensif mengingat persoalan tersebut akan mempengaruhi stabilitas keamanan regional. Pembangunan Kanal Kra masih belum menemui titik temu atau masih berada pada situasi yang tidak pasti, diplomasi pertahanan Indonesia sebaiknya tidak mencampuri perencanaan pembangunan Kanal Kra, tidak termotivasi untuk mendorong isu tersebut ke level regional ASEAN, dan tetap mengedepankan implementasi kebijakan diplomasi pertahanan yang telah berjalan, seperti patroli militer bersama negaranegara ASEAN di Selat Malaka, terutama bersama Singapura dan Malaysia. Langkah diplomasi pertahanan Indonesia disarankan agar tetap sesuai dengan kepentingan nasional dan tidak menimbulkan langkahlangkah provokasi mengingat pro dan kontra terkait Kanal Kra berdampak pada stabilitas keamanan dan hubungan antar negara-negara di Asia Tenggara.

\section{DAFTAR PUSTAKA}

Biasane, A. N., Fauzi, A., Monintja, \& Soedharma, D. (2011). Policy on management of 
neighboring state small Islands: case of Sangihe archipelago North Sulawesi. TT Kebijakan pengelolaan pulau kecil perbatasan berbasis geopolitik, daya dukung ekonomi dan lingkungan: kasus pulau-pulau kecil perbatasan Kepulauan S. Jurnal Teknologi Perikanan Dan Kelautan, 2(1), 21-40. Retrieved from https://login.proxy.lib.duke.edu/login?url=https://search.proquest.com/docview/155161 7597? accountid=10598\%0Ahttp://pm6mt7vg3j.search.serialssolutions.com/directLink? \&atitle=Policy+on+management+of+neighboring+state+small+Islands $\% 3 \mathrm{~A}+$ case + of + Sangihe+archipe

Gita, A., Persada, K., \& Setyawanta, L. T. (2021). Perubahan Jalur Pelayaran Terhadap Peta Perekonomian Asia Tenggara Dampak Pembangunan Terusan Kra Thailand. Journal of Marine Research, 10(1), 131-137.

Hambalie, W. (2020). Kebijakan Luar Negeri Sebagai Manifestasi Eksistensi Negara. Jurnal Sentris, 2(2), 47-56. https://doi.org/10.26593/sentris.v2i2.4138.47-56

Hamzah, B. A., Forbes, V. L., Jalil, J. A., \& Basiron, M. N. (2014). The maritime boundaries of Malaysia and Indonesia in the Malacca strait: An appraisal. Australian Journal of Maritime \& Ocean Affairs, 6(4), 207-226. https://doi.org/10.1080/18366503.2014.956856

Heng, Z., \& Yip, T. L. (2017). Impacts of Kra Canal and its toll structures on tanker traffic. Maritime Policy and Management, 45(1), 125-139. https://doi.org/10.1080/03088839.2017.1407043

Ho, J. H. (2009). Enhancing safety, security, and environmental protection of the straits of Malacca and Singapore: The cooperative mechanism. Ocean Development and International Law, 40(2), 233-247. https://doi.org/10.1080/00908320902864854

Kartini, I. (2016). Kebijakan Jalur Sutra Baru Cina Dan Implikasinya Bagi Amerika Serikat. Jurnal Kajian Wilayah, 6(2), 131-147. Retrieved from http://ejournal.lipi.go.id/index.php/jkwpsdr/article/view/334

Miles, M. B., Huberman, A. M., \& Saldana, J. (2014). Qualitative Data Analysis: A Methods Sourcebook. London: SAGE Publications.

Moleong, L. J. (2017). Metodologi Penelitian Kualitatif. Bandung: PT Remaja Rosdakarya.

Monika, F., Baiquni, M., \& Hadi, M. P. (2020). Indonesia's maritime strategy facing The Kra Isthmus Canal agenda. Jurnal Pendidikan Geografi, 25(1), 39-53. https://doi.org/10.17977/um017v25i12020p039

Mukhtar. (2013). Metode Praktis Penelitian Deskriptif Kualitatif. Jakarta: Reference.

Peng Er, L. (2018). Thailand's Kra Canal Proposal and China's Maritime Silk Road: Between Fantasy and Reality? Asian Affairs(UK), 45(1), 1-17. https://doi.org/10.1080/00927678.2017.1410403

Radityo, F., Rara, G., Amelia, I., \& Efraim, R. (2019). Geopolitik Tiongkok Di Kawasan Asia Tenggara: Jalur Perdagangan (Obor). Jurnal Asia Pacific Studies, 3(1), 84. https://doi.org/10.33541/japs.v3i1.1073

Rahawarin, M. F., Ahmad, I., \& Octavian, A. (2019). Pengaruh Konflik dan Anggaran Pertahanan Terhadap Pertumbuhan Ekonomi di Asia Tenggara. Jurnal Ekonomi Pertahanan, 5(2), 231-252.

Rahmadani, S., Kusmanto, H., \& Warjio. (2019). Strategi Cina menghadapi “ Malacca Dilemma " dalam Rangka Pengamanan Jalur Energy Cina di Selat Malaka " Malacca Dilemma " and Oil Transport: China's Strategy and The Sea Lane Security in The Malacca Strait. Jurnal Pendidikan Ilmu Ilmu Sosial, 11(1), 141-148.

Rahman, N. S. F. A., Salleh, N. H. M., Najib, A. F. A., \& Lun, V. Y. H. (2016). A descriptive method for analysing the Kra Canal decision on maritime business patterns in Malaysia. Journal of Shipping and Trade, 1(13), 1-16. https://doi.org/10.1186/s41072-016-0016- 
0

Ridwan, M., \& Yulianto, E. (2010). Kompetensi Program Studi Diploma Teknik Perkapalan dalam Industri Maritim Indonesia. Gema Teknologi, 16(1), 16-21.

Rouillard, M., \& Saito, A. (2013). Building the Kra Canal and Southeast Asian Development. Executive Intelligence Review, 16-24.

Sa'adah, A. F., Fauzi, A., \& Juanda, B. (2017). Prediction ofFuel Supply and Consumption in Indonesia with System Dynamics Model. Jurnal Ekonomi Dan Pembangunan Indonesia, 17(2), 118-137.

Sartono, Prakoso, L. Y., \& Suseto, B. (2019). Perimbangan Kekuatan Laut Indonesia Masa Kini Dihadapkan dengan Geopolitik Kawasan Asia Pasifik. Strategi Pertahanan Laut, 5(2), 87-114.

Sujarweni, V. W. (2014). Metode Penelitian: Lengkap, Praktis, dan Mudah Dipahami. Yogyakarta: Pustaka Baru Press.

Sulong, R. S. (2012). The Kra Canal and Southeast Asian Relations. Journal of Current Southeast Asian Affairs, 31(4), 109-125. https://doi.org/10.1177/186810341203100405

Trommer, S. (2014). Legal Opportunity in Trade Negotiations: International Law, Opportunity Structures and the Political Economy of Trade Agreements. New Political Economy, 19(1), 1-20. https://doi.org/10.1080/13563467.2012.753520

Wayne, C. S. (2020). Impact of the Kra Canal on Singapore's Security. The United States Army Command and General Staff College. 